\title{
A quantitative study of weak noncovalent interactions in two pyridine isomers containing nitrile and thiophene moieties: a combined $\mathrm{X}$-ray and theoretical investigation
}

\author{
MANI UDAYAKUMAR ${ }^{\mathrm{a}}$, MARGARITA CERÓN ${ }^{\mathrm{b}}$, PAULINA CEBALLOS $^{\mathrm{b}}$, \\ PERUMAL VENKATESAN $^{\mathrm{b}}, \mathrm{M} \mathrm{JUDITH} \mathrm{PERCINO}^{\mathrm{b}}$ and SUBBIAH THAMOTHARAN ${ }^{\mathrm{a}, *(1)}$ \\ ${ }^{a}$ Biomolecular Crystallography Laboratory, Department of Bioinformatics, School of Chemical and \\ Biotechnology, SASTRA Deemed University, Thanjavur 613 401, India \\ ${ }^{b}$ Unidad de Polímeros y Electrónica Orgánica, Instituto de Ciencias, Benemérita Universidad Autónoma de \\ Puebla, Val3-Ecocampus Valsequillo, Independencia O2 Sur 50, San Pedro Zacachimalpa, Pue., Mexico \\ E-mail: thamu@scbt.sastra.edu
}

MS received 8 February 2019; revised 26 April 2019; accepted 3 May 2019

\begin{abstract}
Single crystals of two pyridine isomers containing cyano and thiophene moieties \{ systematic names: (Z)-2-(pyridine-2-yl)-3-(thiophen-2-yl)acrylonitrile, $\mathrm{C}_{12} \mathrm{H}_{8} \mathrm{~N}_{2} \mathrm{~S}$, I and (Z)-2-(pyridine-3-yl)-3-(thiophen-2yl)acrylonitrile, $\mathrm{C}_{12} \mathrm{H}_{8} \mathrm{~N}_{2} \mathrm{~S}$, II \} were obtained from ethanol-cyclohexane mixture. The thiophene ring was found to be disordered over two orientations (syn and anti) in II. The potential energy surface scan of thiophene ring rotation suggests that the syn conformer is more stable by $\approx 4 \mathrm{kcal} \mathrm{mol}^{-1}$ than that of the anti-conformer. The optimized structures obtained using the DFT method (M06-2X/cc-pVTZ level of theory) show a high degree of similarity with the experimental structures. A detailed experimental and theoretical analysis on the intra- and intermolecular interactions observed in these structures is reported. The molecules arranged in the crystalline state are completely different in I and II. Intermolecular interactions are qualitatively analyzed using Hirshfeld surface and its associated 2D fingerprint plots. The intermolecular interaction energies of different molecular pairs are calculated using the PIXEL method. Several weak non-covalent interactions such as $\mathrm{C}-\mathrm{H} \cdots \mathrm{N}, \mathrm{C}-\mathrm{H}$ $\cdots \pi, \mathrm{C}-\mathrm{H} \cdots \mathrm{S}, \pi \cdots \pi$ and $\mathrm{S} \cdots \mathrm{N}$ contacts play a vital role in the stabilization of crystal structures. These interactions are further explored by the topological analysis of the electron density based on the quantum theory of the atoms-in-molecules approach.
\end{abstract}

Keywords. Pyridine; nitrile; thiophene; PIXEL; QTAIM; MESP.

\section{Introduction}

An understanding of weak noncovalent interactions in the context of crystal packing is an important aspect of crystal engineering. Such an understanding will help us to design new solids with desired physicochemical properties. ${ }^{1}$ The hydrogen bonds and $\pi-\pi$ interactions are well-acknowledged in crystal engineering, structural chemistry and structural biology among other weak noncovalent interactions. ${ }^{2-6}$ To understand the role of weak noncovalent interactions especially in the absence of a strong donor group, we synthesized two pyridine isomers, which contain cyano and thiophene functionalities, and determined their crystal structures at low temperature.

Many pharmaceuticals contain a cyano(-CN) functionality and are prescribed for a diverse variety of medicinal indications. ${ }^{7}$ The cyano functionality was used as a substructure to search the drug bank (www. drugbank.ca), ${ }^{8}$ which revealed 243 compounds, most of which are approved drugs. Further, the drugs for type 2 diabetes, namely, rosiglitazone and pioglitazone, contain pyridine nucleus. ${ }^{9}$ Interestingly, one of the approved drugs, i.e., milrinone, contains bothpyridine

\footnotetext{
*For correspondence

Electronic supplementary material: The online version of this article (https://doi.org/10.1007/s12039-019-1636-3) contains supplementary material, which is available to authorized users.
} 
and cyano functionalities, which is used for treating heart failure. ${ }^{10}$ Thiophene scaffold is also present in many drugs, which have proven to be toxic for humans and animals. ${ }^{11}$

On the other hand, the conjugated organic compounds with cyano substituent display excellent optical and electrical properties due to their high electron affinities. ${ }^{12}$ Some of the poly( $p$-pyridine $)$ - and poly( $p$ pyridylvinylene)-based polymers have been reported as emitting chromophores ${ }^{13-15}$ and some nitrile containing polymers have been reported as semiconductors. ${ }^{16}$ In view of this, we have studied the optical properties and crystal structures of several acrylonitrile derivatives earlier. ${ }^{13,17-20}$

We present herein the crystal and molecular structures of two pyridine isomers featuring cyano and thiophene moieties A detailed investigation of weak non-covalent interactions present in them is carried out using the PIXEL method ${ }^{21-23}$ along with the Bader's quantum theory of atoms-in-molecules (QTAIM) approach. ${ }^{24}$ This study helps to understand the nature of various non-covalent interactions and their roles in the solid state. The Hirshfeld surface analysis ${ }^{25}$ and the two-dimensional fingerprint plots ${ }^{26,27}$ are performed to delineate the differences and similarities in terms of non-covalent close contacts between these two pyridine isomers.

\section{Experimental}

\subsection{Synthesis and crystallization}

A mixture of 2-thiophencarboxaldehyde $(0.23 \mathrm{~mL}, 2.0 \mathrm{mmol})$, $10 \mathrm{~mL}$ of ethanol and $2.0 \mathrm{mmol}(0.25 \mathrm{~mL})$ of 2-pyridylacetonitrile was prepared. This mixture was maintained at room temperature, and $\mathrm{KOH}(3.0 \mathrm{mmol}, 0.168 \mathrm{~g})$ was added to it. The resultant reaction mixture was kept for $5 \mathrm{~h}$ until the formation of white powder (compound I). Compound II was prepared similarly except that 3-pyridylacetonitrile (2.0 $\mathrm{mmol}, 0.249 \mathrm{~mL}$ ) was used instead of 2-pyridylacetonitrile (Scheme 1). These two compounds were characterized by ${ }^{1} \mathrm{H}-\mathrm{NMR},{ }^{13} \mathrm{C}-\mathrm{NMR}$ and FT-IR spectroscopy. Single crystals of I and II were obtained from the recrystallization using a mixture of ethanol:cyclohexane $(2: 1 \mathrm{v} / \mathrm{v})$. The spectral details are given in the supplementary section (Figures S1-S6, Supplementary Information).

\subsection{Structure solution and refinement}

Suitable crystals of I and II were chosen for single crystal X-ray diffraction study. Both compounds were solved by the direct methods using the program SHELXS-2013. ${ }^{28}$ All the non-hydrogen atoms were refined anisotropically using SHELXL-2014/7. ${ }^{29}$ The H atoms were fixed at the calculated

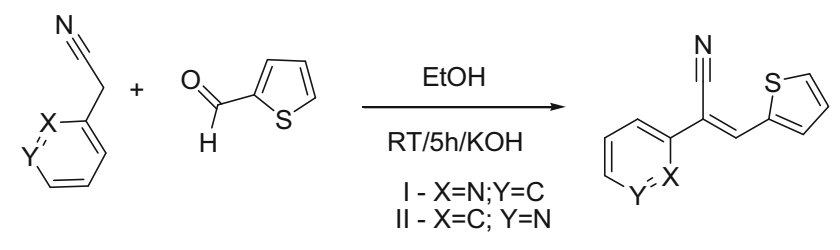

Scheme 1. Synthesis of the title compounds.

positions with $U_{\text {iso }}(\mathrm{H})=1.2 U_{\text {eq }}(\mathrm{C})$. In II, the thiophene ring was disordered over two orientations with a refined occupancy ratio of $0.838(3): 0.162(3)$. The crystal of II was found to be non-merohedrally twinned and the twin relationship corresponds to a twofold axis. The BASF scale factor was refined to be $0.383(2)$. Only the major disordered component (hereafter IIA) is considered for further analysis. The crystal data and structure refinement parameters are presented in Table 1. The ORTEP diagrams and the interacting dimeric structures were drawn using the programs PLATON ${ }^{30}$ and MERCURY, ${ }^{31}$ respectively.

\subsection{Hirshfeld surface analysis (HS)}

To visualize and quantify various intermolecular interactions present in I and IIA, we performed HS analysis to obtain 2D fingerprint plots using the program CrystalExplorer $17 .{ }^{32}$ The $\mathrm{X}$-ray geometries after resetting the bond lengths involving $\mathrm{H}$ atoms were $(\mathrm{C}-\mathrm{H}=1.083 \AA)$ used for the calculation. The HS was mapped with various properties such as $d_{\text {norm }},{ }^{27}$ shape index, ${ }^{33}$ and deformation density.

\subsection{PIXEL energy calculation}

The lattice energy for the crystal structures of I and IIA and intermolecular interaction energies $\left(E_{\mathrm{tot}}\right)$ for different dimers in these structures were calculated using the PIXELC module in the CLP package (Version 3.0, November 2015). ${ }^{23}$ For a comparative purpose, the intermolecular interaction energy for different dimers (at their crystal structure geometry) identified from the PIXEL method was computed using the M06-2X-D3/cc-pVTZ level of theory. These energies $\left(\Delta E_{\mathrm{CP}}\right)$ were corrected for basis set superposition error (BSSE) using the counterpoise method. ${ }^{34}$

\subsection{Structural optimization and rigid potential energy surface scan}

The structural optimization was performed for both $\mathbf{I}$ and IIA without any geometrical constraints using the Gaussian09 program ${ }^{35}$ at M06-2X/cc-pVTZ level of theory. ${ }^{36}$ The empirical dispersion correction (D3) was included as proposed. ${ }^{37}$ The optimized structures were further subjected to the vibrational frequency calculation to assess the minimum energy conformer on the potential energy surface (PES). Since the thiophene ring was disordered over two orientations (syn and anti conformers are defined based on the rotation of thiophene 
Table 1. Crystal data and refinement parameters for compounds I and II.

\begin{tabular}{|c|c|c|}
\hline & I & II \\
\hline \multicolumn{3}{|l|}{ Crystal data } \\
\hline Chemical formula & $\mathrm{C}_{12} \mathrm{H}_{8} \mathrm{~N}_{2} \mathrm{~S}$ & $\mathrm{C}_{12} \mathrm{H}_{8} \mathrm{~N}_{2} \mathrm{~S}$ \\
\hline $\mathrm{Mr}$ & 212.26 & 212.26 \\
\hline Crystal system, space group & Orthorhombic, $\mathrm{Pbca}$ & Monoclinic, $P 2{ }_{1} / \mathrm{n}$ \\
\hline Temperature $(\mathrm{K})$ & $110(2)$ & $110(2)$ \\
\hline$a, b, c(\AA)$ & $6.8798(3), 13.8842(7), 20.9606(9)$ & $13.6152(8), 4.7297(3), 16.2431(10)$ \\
\hline$\alpha, \beta, \gamma\left(^{\circ}\right)$ & $90,90,90$ & $90,105.293(6), 90$ \\
\hline$V\left(\AA^{3}\right)$ & 2002.17(16) & $1008.95(11)$ \\
\hline$Z$ & 8 & 4 \\
\hline Radiation type & Mo $K \alpha$ & $\mathrm{Cu} K \alpha$ \\
\hline$\mu\left(\mathrm{mm}^{-1}\right)$ & 0.285 & 2.54 \\
\hline Crystal size & $0.36 \times 0.23 \times 0.19$ & $0.46 \times 0.09 \times 0.06$ \\
\hline \multicolumn{3}{|l|}{ Data collection } \\
\hline Diffractometer & SuperNova, Dual, $\mathrm{Cu}$ at zero, Atlas & SuperNova, Dual, $\mathrm{Cu}$ at zero, Atlas \\
\hline Absorption correction & Analytical & Analytical \\
\hline$T_{\min }, T_{\max }$ & $0.935,0.960$ & $0.489,0.880$ \\
\hline No. of measured, independent & $8098,2296,1905$ & $6405,2209,1915$ \\
\hline $\begin{array}{l}\text { and observed }[I>2 \sigma(I)] \\
\text { reflections }\end{array}$ & & \\
\hline$R_{\text {int }}$ & 0.031 & 0.033 \\
\hline$(\sin \theta / \lambda)_{\max }\left(\AA^{-1}\right)$ & 0.650 & 0.616 \\
\hline \multicolumn{3}{|l|}{ Refinement } \\
\hline$R\left[F^{2}>2 \sigma\left(F^{2}\right)\right], w R\left(F^{2}\right), S$ & $0.040,0.102,1.07$ & $0.043,0.117,1.07$ \\
\hline No. of reflections & 2296 & 2209 \\
\hline No. of parameters/restraints & $136 / 0$ & $174 / 160$ \\
\hline$\Delta \rho_{\max }, \Delta \rho_{\min }\left(\mathrm{e} \AA^{-3}\right)$ & $0.36,-0.36$ & $0.46,-0.31$ \\
\hline CCDC No. & 1892110 & 1892109 \\
\hline
\end{tabular}

ring) in II, we performed rigid PES scan using B3LYP/6$31 \mathrm{G}(\mathrm{d})$ level of theory ${ }^{38}$ for the C7-C8-C9A-C10A torsion angle from 0 to $360^{\circ}$ with an increment of $5^{\circ}$ to identify the stable conformer.

\subsection{QTAIM analysis}

The topological properties were calculated for all the dimers in I and IIA using AIMALL package (T. Keith, AIMAll version 16.05.18, 2016). From the calculation, we obtained electron density $(\rho)$, Laplacian of electron density $\left(\nabla^{2} \rho\right)$, potential energy density $\left(V_{b}\right)$ and kinetic energy density $\left(G_{b}\right)$ and total energy density $\left(\mathrm{H}_{\mathrm{b}}\right)$ for noncovalent interactions present in different molecular dimers in these two structures. In order to evaluate the strengths of different interactions, we computed the dissociation energy $\left(D E_{\text {int }}\right)$ for the interaction based on the empirical approach proposed earlier. ${ }^{39}$

\section{Results and Discussion}

\subsection{General description of structures of I and II}

In the present investigation, we examined crystal structures of two pyridine isomers to study the role of weak noncovalent interactions in the solid state and to identify the similarities and differences in the crystal packing. Both compounds crystallize in the centrosymmetric space groups and one molecule per asymmetric unit in each of this compound. From the X-ray analysis, we found that the structure of $\mathbf{I}$ is well-ordered. The thiophene ring is disordered over two orientations in II (Figure 1). The major disordered component (labeled as A) of the thiophene ring is in syn conformation concerning the orientation of $\mathrm{S}$ and $\mathrm{CN}$ group, while the minor component (labeled as B) adopts anti conformation. To identify the stable conformer of II, we performed rigid PES scan for the torsion angle C7-C8-C9A-C10A. The result suggests that the syn conformer is found to be more stable than the anti conformer (Figure S7, Supplementary Information). The relative energy difference between syn and anti conformers is found to be $4.7 \mathrm{kcal} \mathrm{mol}^{-1}$.

The selected torsion angles that describe the conformations of molecules I and IIA are given in Table S1 (Supplementary Information). In I, the thiophene ring is slightly twisted $\left(8.22(4)^{\circ}\right)$ with respect to the mean plane of the 2-pyridyl ring. The central moiety formed by atoms $\mathrm{C} 1-\mathrm{C} 7-\mathrm{C} 8-\mathrm{C} 9$ makes dihedral angles 

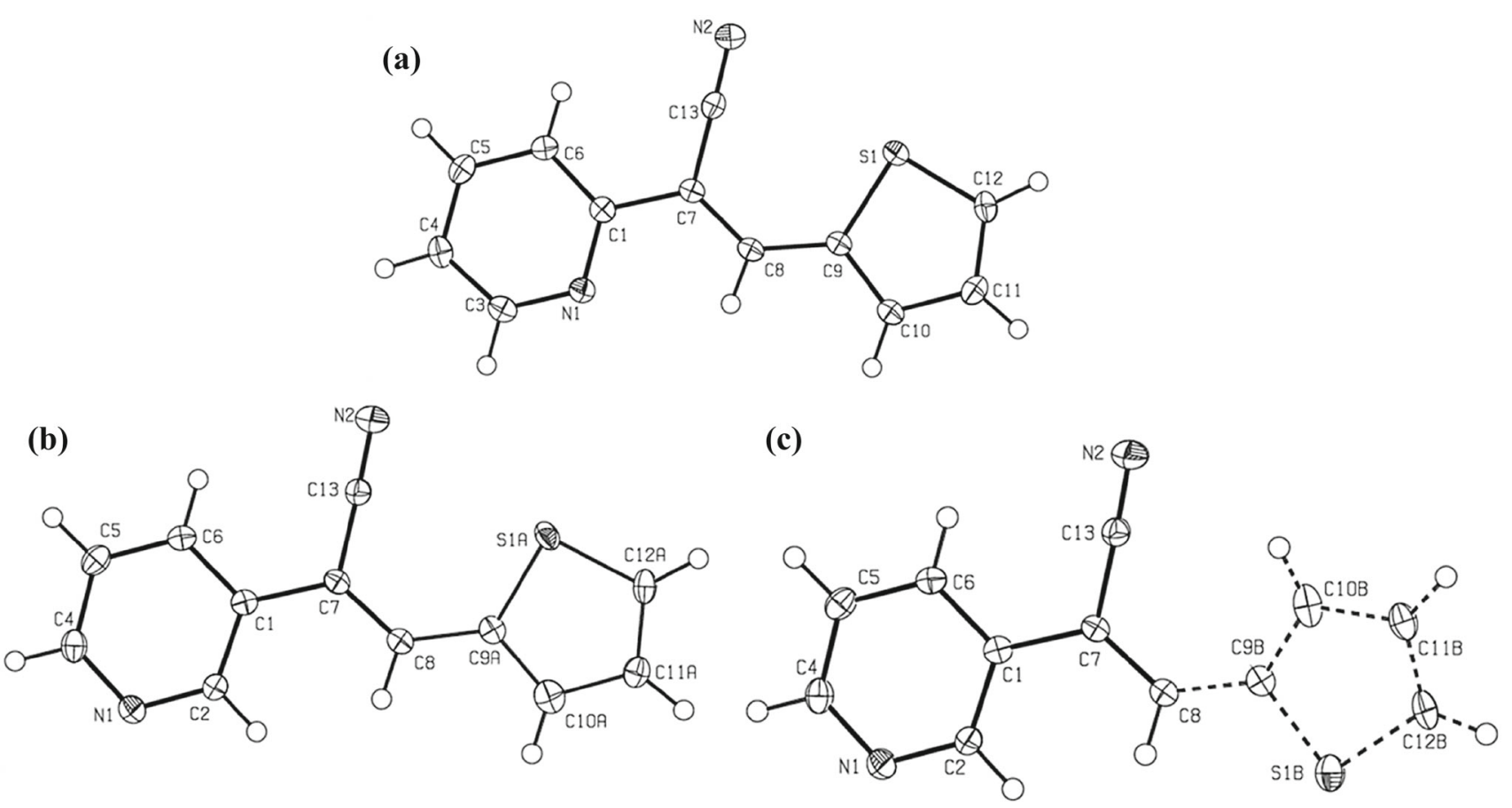

Figure 1. ORTEP representation of (a) compound I, (b) the major disordered component of compound II (IIA), and (c) the minor disordered component of compound II (IIB). Displacement ellipsoids are drawn at the $50 \%$ probability level with the atom-labelling scheme.

of $6.04(1)$ and $13.97(1)^{\circ}$ with the mean planes of thiophenyl and 2-pyridyl rings, respectively. In IIA, the orientation of the thiophene ring is similar to that in I with respect to the mean plane of the 3-pyridyl ring.

\subsection{Quantitative molecular electrostatic potential map (MESP)}

The molecular electrostatic potential maps were generated for I and IIA at their crystal structure geometries from the corresponding wave functions using WFA-SAS program. ${ }^{40}$ The locations of the most positive $\left(\mathrm{V}_{\mathrm{s}, \max }\right.$, black hemisphere) and negative potentials $\left(\mathrm{V}_{\mathrm{s}, \min }\right.$, blue hemisphere) are shown in Figure S8 (Supplementary Information). We found that the distribution of electrostatic potentials is varied in the central region of the molecule. It is noted that the cyano N2 atom has a more electronegative potential $\left(\mathrm{V}_{\mathrm{s}, \min }=\right.$ $-37.59 \mathrm{kcal} \mathrm{mol}^{-1}$ ) in I than in the structure of IIA. In contrast, the pyridyl N1 atom has a greater electronegative potential in IIA as compared to the structure of $\mathbf{I}$. In the case of $\mathbf{I}$, the more positive potential is located on the hydrogen atoms $\mathrm{H} 12$ and $\mathrm{H} 5$ with $\mathrm{V}_{\mathrm{s}, \max }$ values of 25.03 and $23.21 \mathrm{kcal} \mathrm{mol}^{-1}$, respectively. This supports the involvement of these atoms in the formation of intermolecular $\mathrm{C}-\mathrm{H} \cdots \mathrm{N}_{\text {nitrile }}$ and $\mathrm{C}-\mathrm{H} \cdots \pi$ interactions in I. In IIA, the most positive potentials are observed near the surface of H8 and H12A atoms. Again, this endorses the participation of these atoms in the intermolecular $\mathrm{C}-\mathrm{H} \cdots \mathrm{N}_{\text {pyridine }}, \mathrm{C}-\mathrm{H} \cdots \mathrm{N}_{\text {nitrile }}$ and $\mathrm{C}-\mathrm{H} \cdots \pi$ interactions.

\subsection{Intramolecular interactions in I and IIA}

The molecules of I and IIA adopt a slightly distorted planar conformation as observed in many closely related structures. ${ }^{17,18,41,42}$ To characterize the intramolecular interactions present in these structures, we performed QTAIM analysis for both X-ray and optimized molecules (Figure S9, for topological properties, see Table S2, Supplementary Information). The results suggest that there is a $(3,-1)$ bond critical point $(\mathrm{BCP})$ observed between $\mathrm{C} 13 \equiv \mathrm{N} 2$ bond and $\mathrm{S} 1$ atom with the electron density $(\rho)$ of $0.076 \mathrm{e} \AA^{-3}$ and the Laplacian of the electron density $\left(\nabla^{2} \rho\right)$ of $0.951 \mathrm{e} \AA^{-5}$ in the $\mathrm{X}$-ray structure of $\mathbf{I}$. This interaction is retained in the optimized structure with similar $\rho$ and $\nabla^{2} \rho$ values. The above contact is also observed in the $\mathrm{X}$-ray structure of IIA in addition to a short $\mathrm{H} 2 \cdots \mathrm{H} 8$ contact with the bond path $\left(R_{\mathrm{ij}}\right)$ of $1.980 \AA$. The topological analysis indicates that the dissociation energy for this $\mathrm{H} \cdots \mathrm{H}$ contact is higher as compared to $\mathrm{C} \equiv \mathrm{N} \cdots \mathrm{S}$ contact. A similar type of close $\mathrm{H} \cdots \mathrm{H}$ contact is observed earlier in different systems as non-electrostatic stabilizing interaction. ${ }^{43-46}$ In the optimized structure of IIA, the pyridyl ring is slightly rotated to avoid this short 

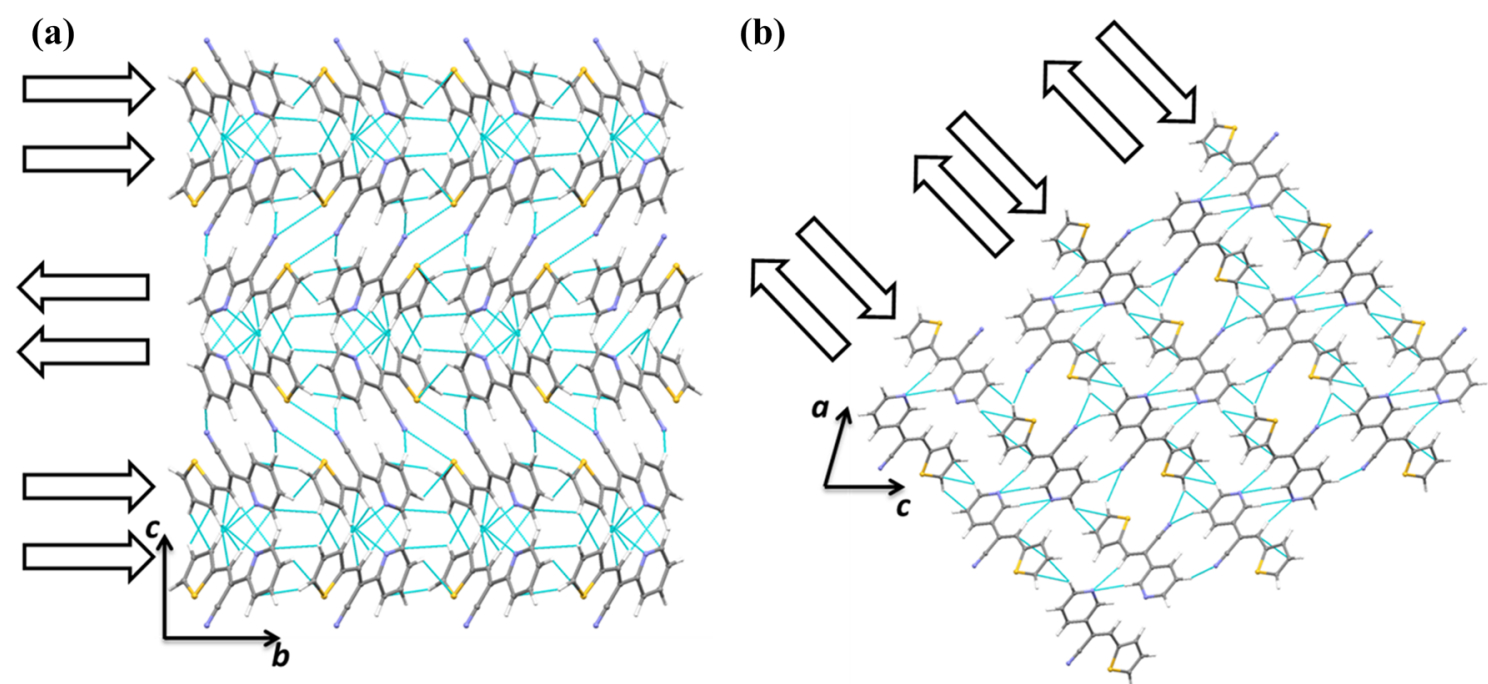

Figure 2. Crystal structures of (a) compound I and (b) the major disordered component IIA.

contact. This observation suggests that the formation of a short intramolecular $\mathrm{H} \cdots \mathrm{H}$ contact is pre-optimized in the crystal. Overall, the presence of conjugation and the existence of intramolecular $\mathrm{C} \equiv \mathrm{N} \cdots \mathrm{S}$ contact may assist molecules to adopt a distorted planar conformation in the crystal.

\subsection{Crystal packing of I and IIA}

In the crystalline state, the basic pattern that is observed is that the molecules of I and IIA form double layers in a head (pyridine)-to-tail (thiophene) fashion (Figure 2). The way the molecules are arranged in the solid state is completely different in I when compared to IIA. For instance, the molecules are oriented in the same direction for the head and tail groups in the double layers (basic pattern) and the adjacent double layers are arranged in an anti-parallel orientation in $\mathbf{I}$. In contrast, molecules are oriented in an anti-parallel configuration in the double layers. One of the layers in the double layers is also oriented in an anti-parallel mode with the neighbouring layers in IIA. The adjacent double layers are interlinked through cyano groups. Analysis of lattice energies suggests that the dispersion energy contributes more towards the stabilization of the crystal structure (Table 2). It is to be noted that the Coulombic contribution is slightly better in IIA.

\subsection{Qualitative analysis of intermolecular} interactions: Hirshfeld surface analysis (HS) and 2D fingerprint plots (FP)

The HS analysis has been performed to understand the nature and the extent of intermolecular interactions
Table 2. Lattice energy (in kcal mol ${ }^{-1}$ ) for compounds I and IIA.

\begin{tabular}{lccccc}
\hline Compound & $E_{\text {Coul }}$ & $E_{\text {pol }}$ & $E_{\text {disp }}$ & $E_{\text {rep }}$ & $E_{\text {tot }}$ \\
\hline I & -12.5 & -5.6 & -34.2 & 24.8 & -27.5 \\
IIA & -15.1 & -5.8 & -33.5 & 26.1 & -28.3
\end{tabular}

observed in the crystal structures of I and IIA and to qualitatively analyze the intermolecular interactions. The relative contributions of various non-covalent interactions in these structures were computed using the 2D fingerprint plots. The brightness of the red spots on the HS implies that the interactions seem to be close contacts. The analysis indicates that the intermolecular $\mathrm{C}-\mathrm{H}$ $\cdots \mathrm{N}_{\text {nitrile }}$ and $\mathrm{S} \cdots \mathrm{N}_{\text {nitrile }}$ interactions are clearly seen on the HS of I (Figure S10 (a), Supplementary Information). It is to be noted that the pale red spots for $\mathrm{H} 8 \cdots \mathrm{H} 10$ contact as compared to the other two. In IIA, at least five intermolecular contacts are $\left(\mathrm{C} 8 \cdots \mathrm{C} 11 \mathrm{~A}, \mathrm{C}-\mathrm{H} \cdots \mathrm{N}_{\text {pyridine }}\right.$, $\mathrm{C}-\mathrm{H} \cdots \mathrm{N}_{\text {nitrile }}$ and $\mathrm{C}-\mathrm{H} \cdots \pi$ ) visible on the HS (Figure S10 (b), Supplementary Information).

The relative contributions of various non-covalent interactions are depicted in Figure 3. The distributions of various non-bonded contacts in the FP plots are remarkably different in I and IIA, and these variations are also reflected on the crystal packings. In both I and IIA, the intermolecular $\mathrm{H} \cdots \mathrm{H}$ interactions have a major contribution to the total HS area and these contacts are $3.2 \%$ higher in IIA when compared to I. This small difference is manifested in the FP (Figure 3). In I, the $\mathrm{H} \cdots \mathrm{H}$ interactions appear as double spikes with the shortest $d_{i}+d_{e}$ distance $\cong 2.2 \AA$, while there are three 
(a)
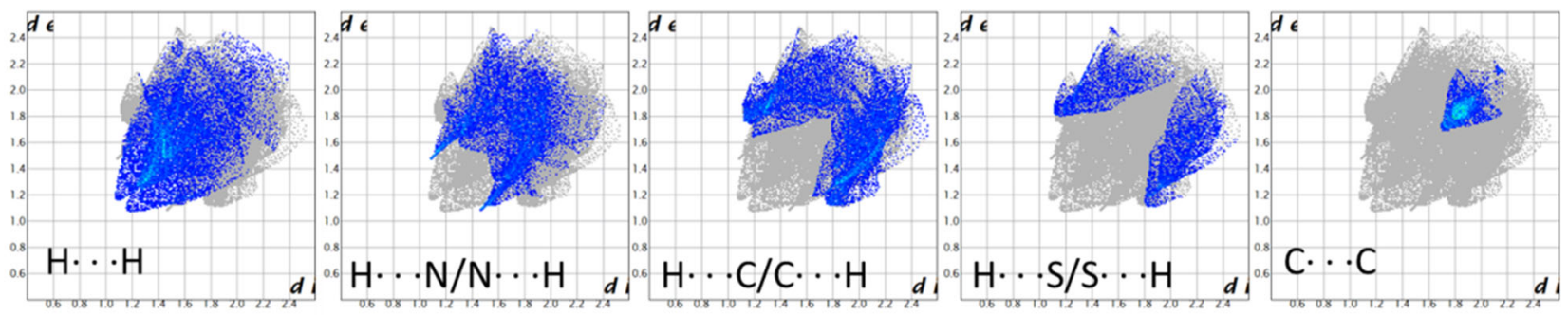

(b)
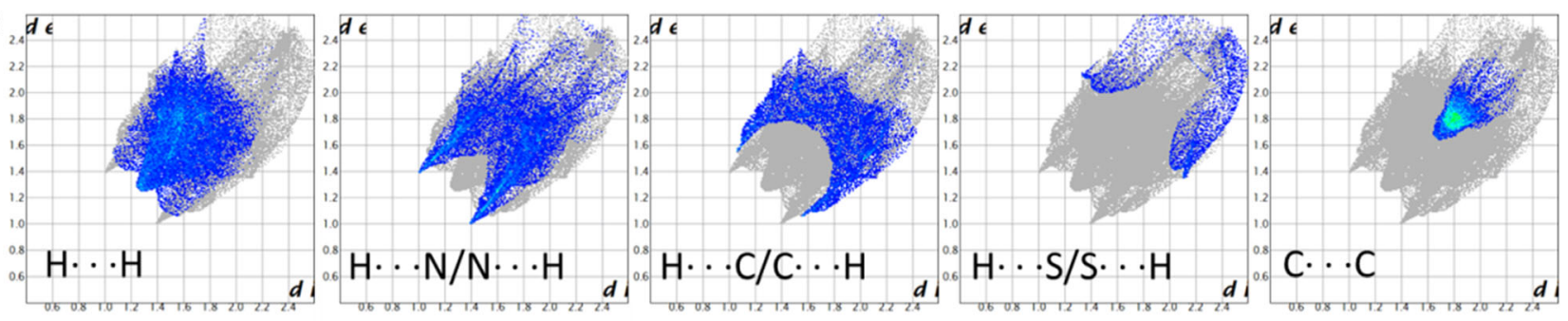

(c)

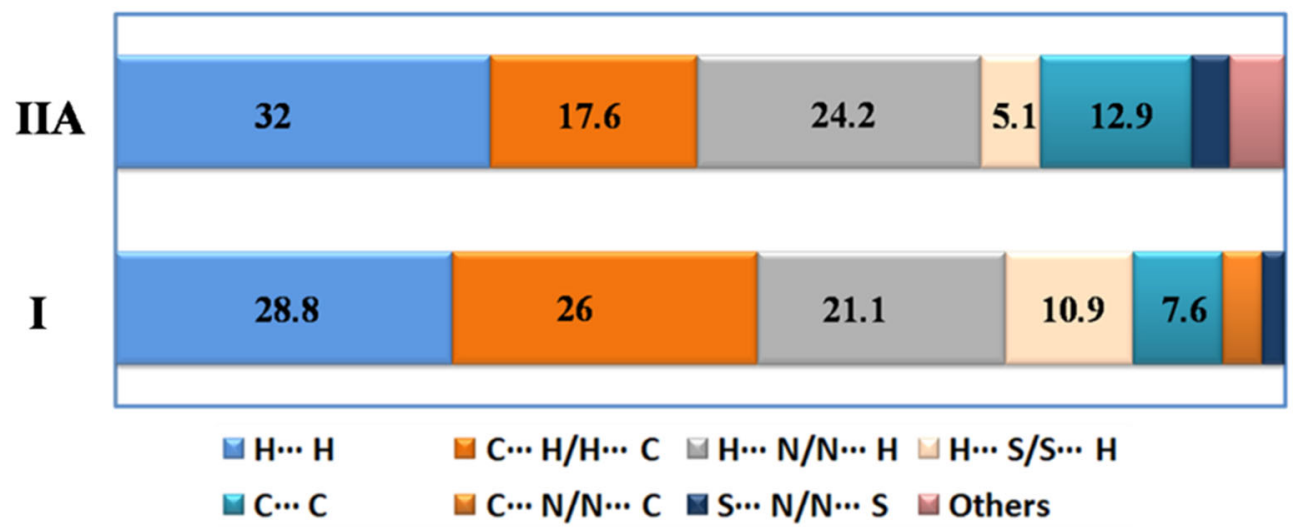

Figure 3. The decomposed two-dimensional fingerprint plots for (a) compound I and (b) compound IIA and (c) the relative contributions of various noncovalent interactions in I and IIA.

spikes in which the center spike is more concentrated in IIA with the closest $d_{i}+d_{e}$ distance $\cong 2.6 \AA$. The next significant contributions come from both $\mathrm{H} \cdots \mathrm{C} / \mathrm{C} \cdots \mathrm{H}$ (26\% in I and $17.6 \%$ in IIA) and $\mathrm{H} \cdots \mathrm{N} / \mathrm{N} \cdots \mathrm{H}(21.1 \%$ in I and $24.2 \%$ in IIA). The $\mathrm{H} \cdots \mathrm{C} / \mathrm{C} \cdots \mathrm{H}$ contacts that are characteristic for $\mathrm{C}-\mathrm{H} \cdots \pi$ interactions, which turn out in the form of wings in I. Further, the $\mathrm{H} \cdots \mathrm{C} / \mathrm{C} \cdots \mathrm{H}$ contacts are slightly longer (shortest $d_{i}+d_{e}$ distance $=$ $\sim 2.9 \AA$ ) in $\mathbf{I}$. The corresponding contacts are observed as a pair of sharp spikes (crescent shape) around $2.6 \AA$ in IIA. The intermolecular $\mathrm{H} \cdots \mathrm{N} / \mathrm{N} \cdot \cdots \mathrm{H}$ contacts appear as double spikes in both I and IIA. However, these contacts are shorter $(\cong 2.4 \AA)$ in IIA than that of I $(\cong 2.6 \AA)$.

These two structures also feature the presence of C . . C contacts $(7.6 \%$ in I and $12.9 \%$ in IIA), which correspond to $\pi \cdots \pi$ interactions and these contacts appear in pale blue and green colour on the diagonal regions around $d_{i}=d_{e}=1.7-1.8 \AA$. Furthermore, the existence of $\pi \cdots \pi$ interactions is also confirmed from the shape index diagram (presence of concave red and convex blue triangles on the surface; Figure S11,
Supplementary Information). Further, the existence of intermolecular $\mathrm{C}-\mathrm{H} \cdots \mathrm{S}$ interaction is clearly seen from the wings in the FP for I $(10.9 \%)$ and the absence of corresponding interaction in IIA (5.1\%). It is of interest to note that these contacts are observed around $2.9 \AA$ in $\mathbf{I}$, while it is ca. $3.4 \AA$ in IIA.

3.6a Quantitative analysis of intermolecular interactions in I: PIXEL and QTAIM: The energetically significant dimers were extracted from the PIXEL calculation. The interaction energies for these dimers (dimeric motifs: M1-M7) ranging from -6.4 to $-2.4 \mathrm{kcal} \mathrm{mol}^{-1}$ (Table 3 and Figure 4). Motif M1 is formed by intermolecular $\mathrm{C}-\mathrm{H} \cdots \mathrm{N}$ interaction (involving $\mathrm{H} 10$ and $\mathrm{N} 1)$ along with one $\mathrm{C}-\mathrm{H} \cdot \mathrm{C}$ and an intermolecular $\mathrm{C} 10-\mathrm{H} 10 \cdots \mathrm{H} 8-\mathrm{C} 8$ contact with an $E_{\text {tot }}$ of $-6.4 \mathrm{kcal} \mathrm{mol}^{-1}$. The dispersion contribution $(65 \%)$ is more significant when compared to the electrostatic contribution (sum of Coulombic and polarization) towards the stabilization of this molecular pair. Further, the existence of these contacts is evaluated by QTAIM analysis (Table 4), and the molecular graphs 


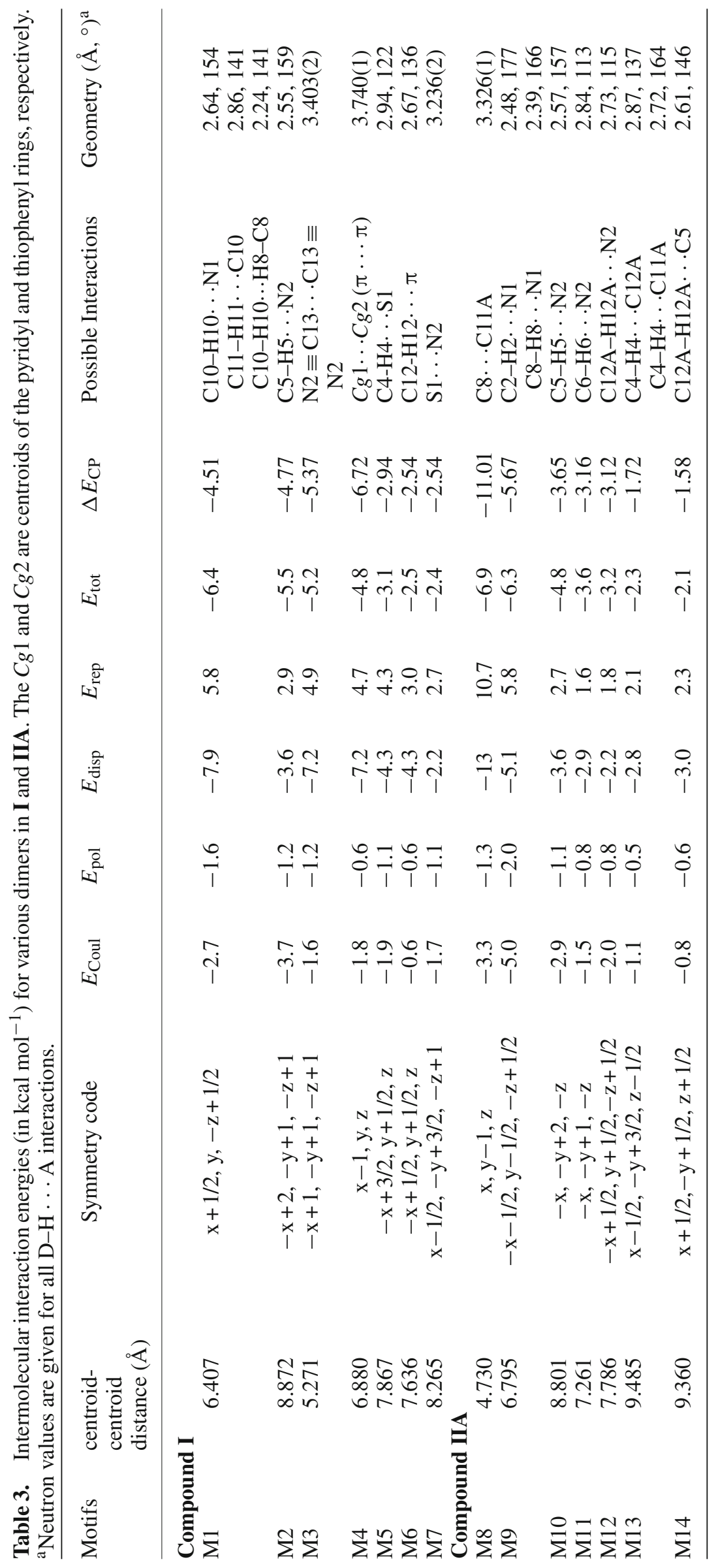


(a)

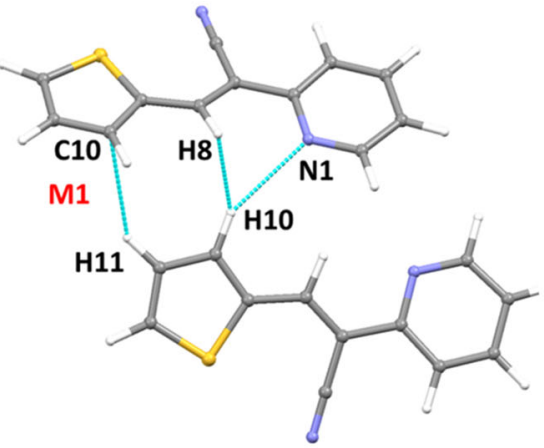

(b)

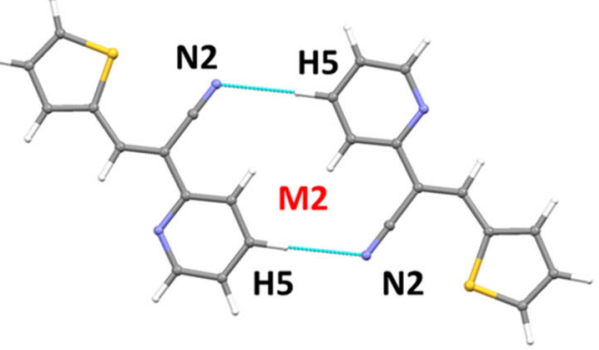

(c)

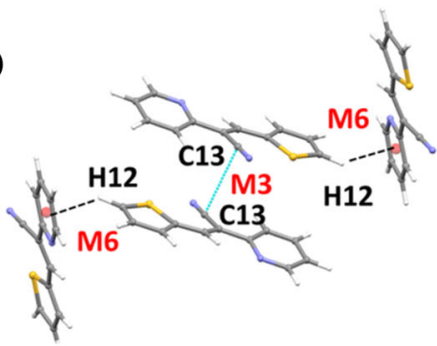

(e)
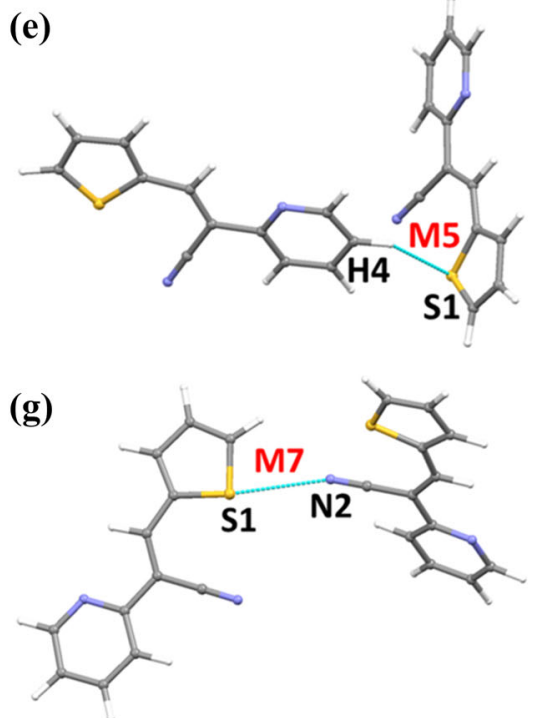

(d)

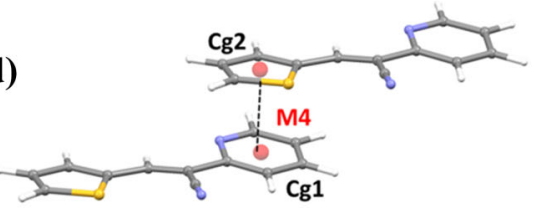

(f)
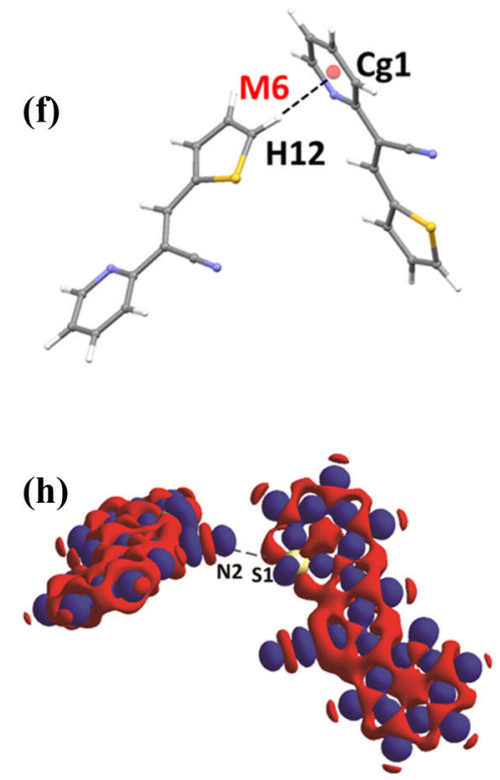

Figure 4. (a-g) Various motifs observed in $\mathbf{I}$ and (h) with the deformation density is showing the existence of intermolecular $\mathrm{N} \cdots \mathrm{S}$ contact in $\mathbf{I}$.

show the intermolecular interactions at the BCP in different molecular pairs of I (Figure S12, Supplementary Information). We note that the destabilization energy for $\mathrm{H} 10 \cdots \mathrm{H} 8$ and $\mathrm{H} \cdots \mathrm{N}_{\text {pyridine }}$ interactions is comparable.

Inversion-related molecules form the molecular dimer (M2, $E_{\text {tot }}:-5.5 \mathrm{kcal} \mathrm{mol}^{-1}$ ), which is held by intermolecular $\mathrm{C}-\mathrm{H} \cdots \mathrm{N}$ interaction in which the $\mathrm{N}$ atom of the cyano group acts as an acceptor. In this case, the electrostatic contribution (58\%) is more than dispersion $(42 \%)$ towards the stabilization. The strength of this interaction $\left(D E\right.$ (int) $\left.=1.21 \mathrm{kcal} \mathrm{mol}^{-1}\right)$ is the same as compared to $\mathrm{C}-\mathrm{H} \cdots \mathrm{N}$ interaction in $\mathrm{M} 1$. The cyano group of one molecule stacks with the cyano group of the adjacent molecule with the shortest distance between two C13 atoms being 3.403(2) $\AA$ in M3. This interaction is predominantly dispersive $(72 \%)$ in nature. From the QTAIM analysis, we found that there is a BCP formed between $\mathrm{C} \equiv \mathrm{N}$ bonds rather than between two $\mathrm{C}$ atoms (Figure S12, Supplementary Information). In M4, the 2-pyridyl and thiophenyl rings are involved in the formation of the $\pi \cdots \pi$ interaction with the $E_{\text {tot }}$ value of $-4.8 \mathrm{kcal} \mathrm{mol}^{-1}$.

Molecules of $\mathbf{I}$ are self-assembled by an intermolecular C4-H4 $\cdots \mathrm{S} 1$ interaction (M5; $E_{\mathrm{tot}}:-3.1 \mathrm{kcal} \mathrm{mol}^{-1}$ ). This interaction links the molecules into a zigzag chain, which runs parallel to the $b$ axis. From the topological analysis, we found that there are two BCPs observed 
Table 4. Topological parameters for different intermolecular interactions in I and IIA. $R_{\mathrm{ij}}$ : Bond path $(\AA), \rho$ : electron density $\left(\mathrm{e} / \AA^{3}\right) ; \nabla^{2} \rho$ : Laplacian of electron density (e $\left.\AA^{5}\right) ; \mathrm{V}_{\mathrm{b}}$ : potential energy density (a.u.); $\mathrm{G}_{\mathrm{b}}$ : kinetic energy density (a.u.); $\mathrm{H}_{\mathrm{b}}$ : total energy density $\left(\mathrm{kJ} \mathrm{mol}^{-1} \mathrm{bohr}^{-3}\right)$ and $D E(\mathrm{int})$ : dissociation energy: $-\mathrm{V}_{\mathrm{b}} \times 0.5(\mathrm{kcal} / \mathrm{mol})$.

\begin{tabular}{|c|c|c|c|c|c|c|c|c|}
\hline Interacting atoms & $R_{i j}$ & $\rho$ & $\nabla^{2} \rho$ & $V_{b}$ & $G_{b}$ & $\frac{\left|-V_{b}\right|}{G_{b}}$ & $H_{b}$ & $D E$ (int) \\
\hline \multicolumn{9}{|l|}{$\begin{array}{l}\text { Compound I } \\
\text { M1 }\end{array}$} \\
\hline $\mathrm{H} 10 \cdots \mathrm{H} 8$ & 2.421 & 0.050 & 0.601 & -0.00393 & 0.005079 & 0.77 & 3.1 & 1.23 \\
\hline $\mathrm{H} 10 \cdots \mathrm{N} 1$ & 2.668 & 0.052 & 0.584 & -0.00387 & 0.004965 & 0.78 & 2.9 & 1.21 \\
\hline $\begin{array}{l}\mathrm{H} 11 \cdots \mathrm{C} 10 \\
\mathbf{M} 2\end{array}$ & 3.051 & 0.037 & 0.426 & -0.00254 & 0.003477 & 0.73 & 2.5 & 0.80 \\
\hline $\begin{array}{l}\text { H5 } \cdots \text { N2 } \\
\text { M3 }\end{array}$ & 2.576 & 0.051 & 0.657 & -0.00386 & 0.005339 & 0.72 & 3.9 & 1.21 \\
\hline $\begin{array}{l}\mathrm{N} 2 \cdots \mathrm{N} 2 \\
\text { M4 }\end{array}$ & 4.647 & 0.037 & 0.441 & -0.0026 & 0.003587 & 0.72 & 2.6 & 0.82 \\
\hline $\mathrm{C} 1 \cdots \mathrm{C} 11$ & 3.688 & 0.036 & 0.398 & -0.00231 & 0.003221 & 0.72 & 2.4 & 0.73 \\
\hline $\begin{array}{l}\text { C5 } \cdots \text { C9 } \\
\text { M5 }\end{array}$ & 4.092 & 0.032 & 0.343 & -0.00184 & 0.002699 & 0.68 & 2.3 & 0.58 \\
\hline $\mathrm{H} 4 \cdots \mathrm{S} 1$ & 2.986 & 0.050 & 0.562 & -0.00375 & 0.004787 & 0.78 & 2.7 & 1.18 \\
\hline $\begin{array}{l}\text { H5 } \cdots \text { S1 } \\
\text { M6 }\end{array}$ & 3.094 & 0.043 & 0.480 & -0.00297 & 0.003978 & 0.75 & 2.7 & 0.93 \\
\hline $\mathrm{H} 12 \ldots \mathrm{C} 6$ & 3.077 & 0.038 & 0.450 & -0.00271 & 0.003688 & 0.73 & 2.6 & 0.85 \\
\hline $\begin{array}{l}\mathrm{H} 11 \cdots \mathrm{C} 3 \\
\text { M7 }\end{array}$ & 2.905 & 0.037 & 0.439 & -0.00266 & 0.003607 & 0.74 & 2.5 & 0.83 \\
\hline $\begin{array}{l}\mathrm{S} 1 \cdots \mathrm{N} 2 \\
\text { Compound IIA } \\
\text { M8 }\end{array}$ & 3.252 & 0.052 & 0.695 & -0.000401 & 0.005610 & 0.72 & 4.2 & 1.26 \\
\hline $\mathrm{C} 8 \cdots \mathrm{C} 11 \mathrm{~A}$ & 3.354 & 0.043 & 0.485 & -0.00293 & 0.003980 & 0.74 & 2.8 & 0.92 \\
\hline C $9 \ldots$ C2 & 4.461 & 0.038 & 0.431 & -0.00231 & 0.003390 & 0.68 & 2.9 & 0.72 \\
\hline $\mathrm{S} 1 \mathrm{~A} \cdots \mathrm{C} 7$ & 3.667 & 0.035 & 0.383 & -0.00223 & 0.003102 & 0.72 & 2.3 & 0.70 \\
\hline $\begin{array}{l}\text { C5 } \cdots \text { C7 } \\
\text { M9 }\end{array}$ & 3.539 & 0.035 & 0.389 & -0.00218 & 0.003104 & 0.70 & 2.5 & 0.68 \\
\hline $\mathrm{H} 8 \cdots \mathrm{N} 1$ & 2.410 & 0.085 & 1.018 & -0.00726 & 0.008910 & 0.81 & 4.4 & 2.28 \\
\hline $\begin{array}{l}\mathrm{H} 2 \cdots \mathrm{N} 1 \\
\mathrm{M} 10\end{array}$ & 2.508 & 0.070 & 0.830 & -0.00579 & 0.007201 & 0.80 & 3.7 & 1.82 \\
\hline $\begin{array}{l}\mathrm{H} 5 \cdots \mathrm{N} 2 \\
\text { M11 }\end{array}$ & 2.592 & 0.050 & 0.637 & -0.00372 & 0.005163 & 0.72 & 3.8 & 1.17 \\
\hline $\begin{array}{l}\mathrm{H} 6 \cdots \mathrm{N} 2 \\
\text { M12 }\end{array}$ & 2.965 & 0.035 & 0.450 & -0.00249 & 0.003577 & 0.69 & 2.9 & 0.78 \\
\hline $\begin{array}{l}\mathrm{H} 12 \mathrm{~A} \cdots \mathrm{N} 2 \\
\text { M13 }\end{array}$ & 2.840 & 0.045 & 0.597 & -0.00339 & 0.004790 & 0.71 & 3.7 & 1.06 \\
\hline $\begin{array}{l}\mathrm{H} 4 \cdots \mathrm{C} 11 \mathrm{~A} \\
\text { M14 }\end{array}$ & 2.905 & 0.050 & 0.538 & -0.00342 & 0.004499 & 0.76 & 2.9 & 1.07 \\
\hline $\mathrm{H} 12 \mathrm{~A} \cdots \mathrm{C} 5$ & 2.634 & 0.054 & 0.608 & -0.00403 & 0.005166 & 0.78 & 3.0 & 1.26 \\
\hline
\end{tabular}

(H4 $\cdots \mathrm{S} 1 ; D E$ (int) : $1.18 \mathrm{kcal} \mathrm{mol}^{-1}$ and $\mathrm{H} 5 \cdots \mathrm{S} 1$; $D E$ (int) : $0.93 \mathrm{kcal} \mathrm{mol}^{-1}$ ). We note that the latter contact is slightly longer than the sum of vDW radii of $\mathrm{H}$ and $\mathrm{S}$. Motif M6 is stabilized by the intermolecular $\mathrm{C}-\mathrm{H} \cdots \pi$ interaction (involving $\mathrm{H} 12$ and $C g 1$; $\mathrm{DE}(\mathrm{H} 12 \ldots \mathrm{C} 6)$ : $0.85 \mathrm{kcal} \mathrm{mol}^{-1}$ and $\left.D E(\mathrm{H} 11 \cdots \mathrm{C} 3): 0.83 \mathrm{kcal} \mathrm{mol}^{-1}\right)$ with the $E_{\text {tot }}$ of $-2.5 \mathrm{kcal} \mathrm{mol}^{-1}$. As shown in Figure 4, the motif M3 is flanked on both sides by motif M6.

The least stabilized dimer in $\mathbf{I}$ is formed by a nonbonded contact between $\mathrm{S} 1$ and $\mathrm{N} 2$ atoms with a distance of 3.236(2) $\AA$ (M7, $\left.E_{\text {tot }}:-2.4 \mathrm{kcal} \mathrm{mol}^{-1}\right)$. The computed deformation density plot around these two atoms is clearly showing that the charge is concentrated at N2, while the charge is found to be depleted at atom S1. (Figure 4(h)). The topological analysis of S1 $\cdots \mathrm{N} 2$ interaction reveals that the magnitudes of the topological parameters $\left(\rho=0.052 \mathrm{e} \AA^{-3}\right.$ and $\left.\nabla^{2} \rho=0.695 \mathrm{e} \AA^{-5}\right)$ at the $\mathrm{BCP}$ are slightly higher as compared to other interactions observed in I. This clearly suggests that the $S \cdots \mathrm{N}$ interaction has a special role in the stabilization of the crystal structure of $\mathbf{I}$. 


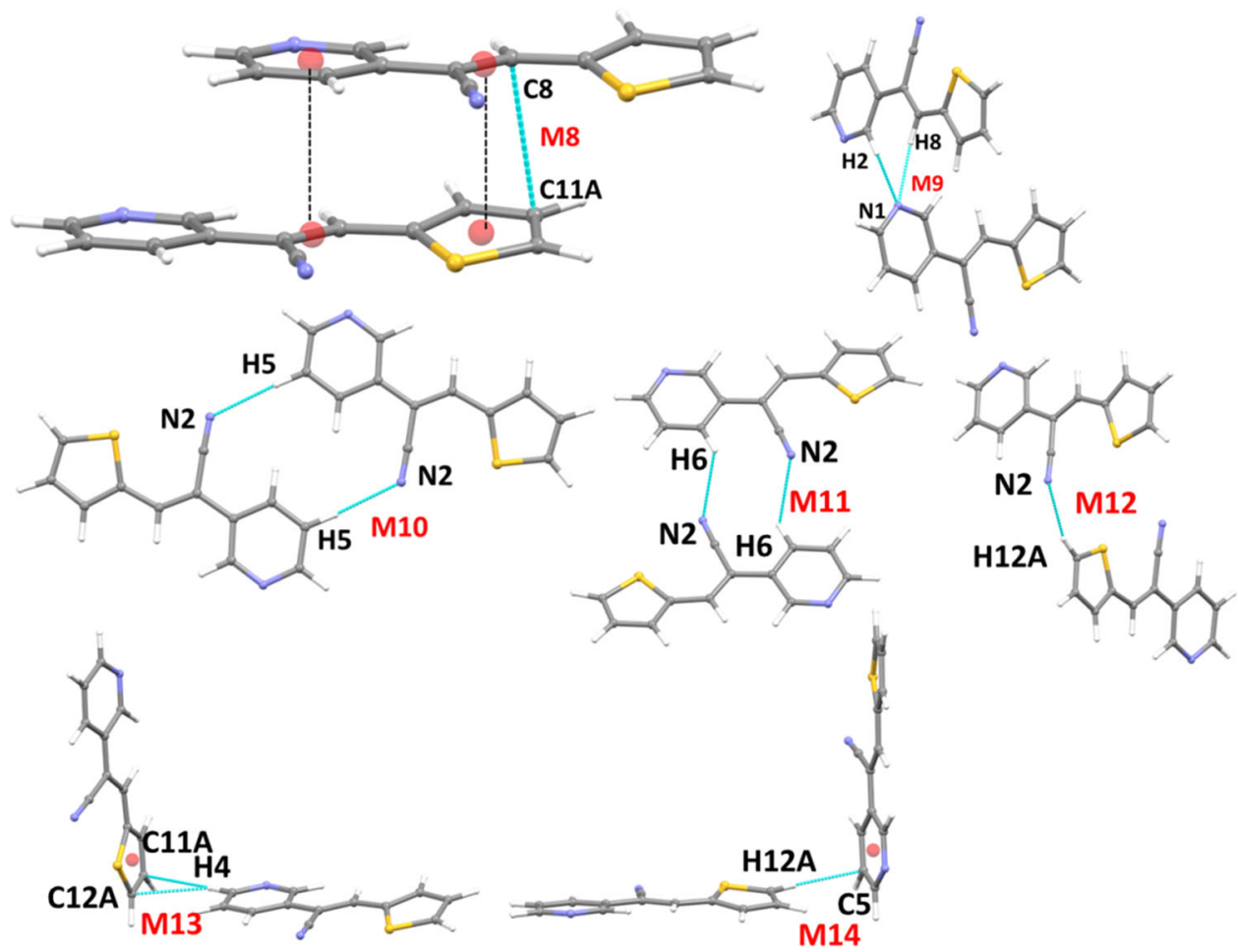

Figure 5. Various motifs observed in IIA and red small spheres are centroid positions of rings and $\mathrm{C} 7=\mathrm{C} 8$ bond.

3.6b Quantitative analysis of intermolecular interactions in IIA: PIXEL and QTAIM: As depicted in Figure 5, there are seven energetically significant dimers identified in IIA from the PIXEL analysis. In the strongest dimer (M8; $\left.E_{\text {tot }}:-6.9 \mathrm{kcal} \mathrm{mol}^{-1}\right)$, molecules are stacked with each other in a displaced parallel mode in which pyridyl and thiophenyl rings are stacked against the vinylic group. The topological analysis confirms the existence of stacking interactions with $D E(C 8 \ldots$ $\mathrm{C} 11 \mathrm{~A}=0.92 \mathrm{kcal} \mathrm{mol}^{-1}$; Table 4 and Figure S13, Supplementary Information). In the next strongest dimer (M9; $E_{\mathrm{tot}}:-6.3 \mathrm{kcal} \mathrm{mol}^{-1} ; 58 \%$ of electrostatic contribution), pyridine $\mathrm{N} 1$ atom acts as an acceptor for two different donor atoms ( $\mathrm{H} 2$ and $\mathrm{H} 8)$. The dissociation energies for these intermolecular $\mathrm{C} 8-\mathrm{H} 8 \cdots \mathrm{N} 1$ and $\mathrm{C} 2-\mathrm{H} 2 \cdots \mathrm{N} 1$ interactions are calculated to be 2.28 and $1.82 \mathrm{kcal} \mathrm{mol}^{-1}$, respectively. The only similarity observed between structures I and IIA is the formation of a closed loop motif through $\mathrm{C}-\mathrm{H} \cdots \mathrm{N}$ interactions (M2 in I and M10 in IIA). The evaluation of the strength of these interactions by the QTAIM analysis suggests that the dissociation energies for these interactions are found to be very similar.

The motif M11 is also formed by the intermolecular $\mathrm{C}-\mathrm{H} \cdots \mathrm{N}$ interaction (involving $\mathrm{H} 6$ and N2) with the $E_{\text {tot }}$ value of $-3.6 \mathrm{kcal} \mathrm{mol}^{-1}$. The contact between $\mathrm{H}$ and $\mathrm{N}$ is slightly longer (by $0.09 \AA$ ) than the sum of the vDW radii of $\mathrm{H}$ and $\mathrm{N}$ atoms. It is noted that the dispersion contribution (56\%) is slightly better than the electrostatic

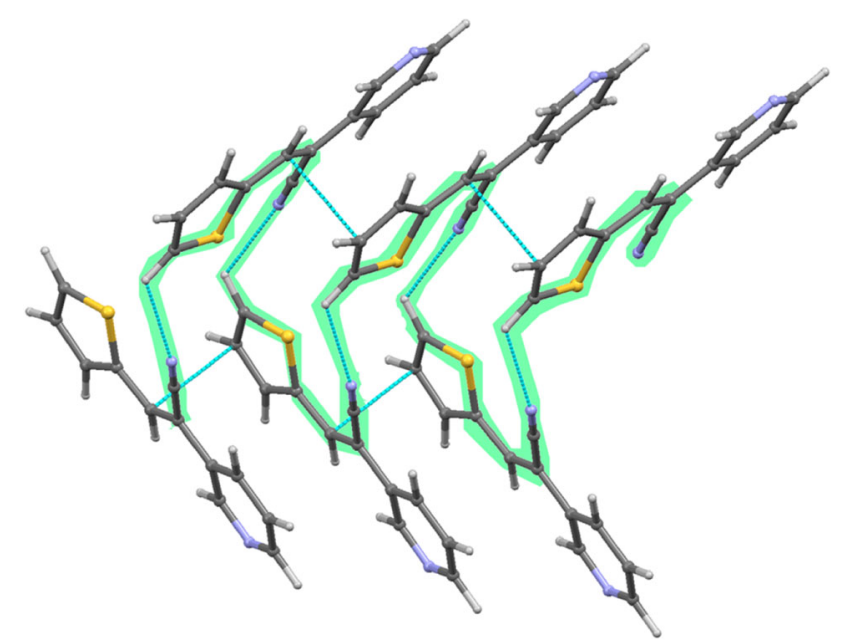

Figure 6. Part of the crystal structure showing a helical chain in IIA.

contribution towards the stabilization of this dimer. The $D E$ for these interactions is found be $0.78 \mathrm{kcal} \mathrm{mol}^{-1}$ for each. Motif M12 ( $E_{\text {tot }}:-3.2 \mathrm{kcal} \mathrm{mol}^{-1} ; 56 \%$ of electrostatic contribution) is formed by intermolecular $\mathrm{C}-\mathrm{H}$ $\cdots \mathrm{N}$ (involving H12A and $\mathrm{N} 2$ interaction). This interaction links the molecules into a helical $C(8)$ chain, and there is a stacking interaction formed between $i$ and $i+2$ molecules in a displaced parallel mode within this chain (Figure 6).

As can be seen from Table 3, motifs M13 and M14 are formed by intermolecular $\mathrm{C}-\mathrm{H} \cdots \pi$ interactions. 
The former motif has an $E_{\text {tot }}$ of $-2.3 \mathrm{kcal} \mathrm{mol}^{-1}$ and the dispersion energy contributes $64 \%$ towards the stabilization, while the latter motif has an $E_{\text {tot }}$ of $-2.1 \mathrm{kcal} \mathrm{mol}^{-1}$ and the dispersion energy contributes $68 \%$ towards the stabilization. Though these two motifs have similar intermolecular interaction energies $\left(E_{\text {tot }}\right)$ and dissociation energies, they differ in terms of the donor group. The donor group in the former motif is the pyridyl ring, while the corresponding group in the latter motif is the thiophenyl ring.

Overall, it should be noted that the positive value of the Laplacian for different non-covalent interactions at the BCP indicates these interactions are considered as closed-shell interactions in I and IIA (Table 4). Moreover, the ratio of $\frac{\left|-V_{b}\right|}{G_{b}}$ appeared to be less than one, which supports the weak nature of non-covalent interactions. Further, the magnitude of electron density values for these interactions in different molecular pairs lies in the range $\left[0.013<\rho\left(\mathrm{e}^{-3}\right)<0.236\right]$ proposed by Koch-Popelier for H-bonds. ${ }^{47,48}$ It is to be noted that the magnitude of the Laplacian for $\mathrm{C}-\mathrm{H} \cdots \mathrm{N}_{\text {nitrile }}, \mathrm{C}-\mathrm{H}$ $\cdots \mathrm{N}_{\text {pyridine }}, \mathrm{H} \cdots \mathrm{H}$ and $\mathrm{S} \cdots \mathrm{N}$ interactions falls within the proposed limit $\left[0.580<\nabla^{2} \rho\left(\mathrm{e} \AA^{-5}\right)<3.355\right]$ in I. In the case of IIA, the intermolecular $\mathrm{C}-\mathrm{H} \cdots \mathrm{N}_{\text {nitrile }}$, $\mathrm{C}-\mathrm{H} \cdots \mathrm{N}_{\text {pyridine }}$ and $\mathrm{C}-\mathrm{H} \cdots \pi$ interactions lie within the suggested limit.

Among various non-covalent interactions observed in these structures (Table 4 ), the $\mathrm{S} \cdots \mathrm{N}$ interaction is found to be strongest $\left(4.2 \mathrm{~kJ} \mathrm{~mol}^{-1} \mathrm{bohr}^{-3}\right)$ based on the total energy density followed by $\mathrm{C}-\mathrm{H} \cdots \mathrm{N}_{\text {nitrile }}, \mathrm{H} \cdots \mathrm{H}, \mathrm{C}-\mathrm{H}$ $\cdots \mathrm{N}_{\text {pyridine }}, \mathrm{C}-\mathrm{H} \cdots \mathrm{S}$ interactions in $\mathbf{I}$. The theoretical topological parameters for the $\mathrm{C}-\mathrm{H} \cdots \mathrm{S}$ interaction in $\mathbf{I}$ are also comparable with the experimental topological parameters for this interaction. ${ }^{49-51}$ For instance, the $\rho$ values obtained from the experiment for the $\mathrm{C}-\mathrm{H}$. . S interaction are in the range of $0.033-0.041 \mathrm{e} \AA^{-3}$. In IIA, the $\mathrm{C}-\mathrm{H} \cdots \mathrm{N}_{\text {pyridine }}$ interaction is found to be the strongest $\left(4.4 \mathrm{~kJ} \mathrm{~mol}^{-1}\right.$ bohr $\left.^{-3}\right)$ followed by $\mathrm{C}-\mathrm{H} \cdots \mathrm{N}_{\text {nitrile }}$ and $\mathrm{C}-$ $\mathrm{H} \cdots \pi$ interactions.

\section{Conclusions}

Two pyridine isomers containing acrylonitrile and thiophene moieties have been synthesized and their crystal structures determined at low temperature by single crystal X-ray diffraction. The thiophenyl ring in the 3-pyridine isomer is disordered over two orientations. Analysis of rigid potential energy scan of thiophenyl ring rotation suggests that the syn conformation is more stable. Though the lattice energies of these isomers are comparable, the molecules are arranged in different ways in the crystalline state. In both cases, the dispersion energy contributes more to the stabilization of the crystal structure. The molecular electrostatic potential map reveals the key regions involved in the intermolecular interactions. In this study, we found that the cyano group plays an important role in linking adjacent double layers in the crystal structure. The qualitative analysis from Hirshfeld surface suggests that the intermolecular $\mathrm{H} \cdots \mathrm{H}, \mathrm{H} \cdots \mathrm{C}$ and $\mathrm{H} \cdots \mathrm{N}$ interactions are the most important contributors to the crystal packing. The non-covalent interactions in these structures are quantified using QTAIM and Koch-Popelier criteria. From this analysis, it can be noted that the $\mathrm{S} \cdots \mathrm{N}$ contact is the strongest among other weak non-covalent interactions in $\mathbf{I}$, while the $\mathrm{C}-\mathrm{H} \cdots \mathrm{N}_{\text {pyridine }}$ interaction is the strongest in IIA. The second strongest interaction is formed by the intermolecular $\mathrm{C}-\mathrm{H} \cdots \mathrm{N}_{\text {nitrile }}$ interaction in both $\mathbf{I}$ and IIA. It can also be seen that there is an intramolecular $\mathrm{C} \equiv \mathrm{N} \cdots \mathrm{S}$ contact, which is found to be important for maintaining the conformation of the molecule.

\section{Supplementary Information (SI)}

The supplementary information includes the following: spectral data (FT-IR and ${ }^{1} \mathrm{H} /{ }^{13} \mathrm{C}$ NMR; Tables S1-S6) for compounds I and II, Table $\mathrm{S} 1$ contains the selected torsion angles, Table S2 summarizes topological parameters of intramolecular interactions (both X-ray and optimized geometries) and S7-S11 show PES for thiophene ring of IIA, molecular graphs of intra-and intermolecular interactions in I and IIA and shape index surface of IIA. Supplementary Information is available at www.ias.ac.in/chemsci.

CCDC-1892110 and 1892109 contain the supplementary crystallographic data for the title compounds I and II, respectively. These data can be obtained freely via http:// www.ccdc.cam.ac.uk/data_request/cif or by e-mailing to data_request@ccdc.cam.ac.uk or by contacting directly the Cambridge Crystallographic Data Centre (12 Union Road, Cambridge CB2 1EZ, UK. Fax: +44 1223 336033).

\section{Acknowledgements}

The authors would like to thank Laboratorio Nacional de Supercoìmputo del Sureste (LNS-BUAP) for the calculus service and the 100184100-VIEP2019 (VIEP-BUAP) and SA/103.5/15/12684 (PRODEP-SEP) projects, as well as Dr. Maxime A. Siegler (Johns Hopkins University) for the assistance with data collection. ST thanks the DST-SERB (SB/YS/LS-19/2014) for financial assistance.

\section{References}

1. Desiraju G R 1989 Crystal Engineering: The Design of organic solids Materials science monographs $1^{\text {st }}$ edn. (Oxford, UK: Elsevier Science)

2. Aakeröy C B, Champness N R and Janiak C 2010 Recent advances in crystal engineering CrystEngComm 1222 
3. Arunan E, Desiraju G R, Klein R A, Sadlej J, Scheiner S, Alkorta I, Clary D C, Crabtree R H, Dannenberg J J, Hobza P and Kjaergaard H G 2011 Definition of the hydrogen bond (IUPAC Recommendations 2011) Pure Appl. Chem. 831619

4. Arunan E, Desiraju G R, Klein R A, Sadlej J, Scheiner S, Alkorta I, Clary D C, Crabtree R H, Dannenberg J J, Hobza P and Kjaergaard, H G 2011 Definition of the hydrogen bond (IUPAC Recommendations 2011) Pure Appl. Chem. 831637

5. Desiraju G R 2011 A bond by any other name Angew. Chem. Int. Ed. $\mathbf{5 0} 52$

6. Desiraju G R and Steiner T 1999 The Weak Hydrogen Bond (Oxford, UK: Oxford University Press)

7. Fleming F F, Yao L, Ravikumar P C, Funk L and Shook B C 2010 Nitrile-containing pharmaceuticals: efficacious roles of the nitrile pharmacophore J. Med. Chem. $\mathbf{5 3 7 9 0 2}$

8. Wishart D S, Feunang Y D, Guo A C, Lo E J, Marcu A, Grant J R, Sajed T, Johnson D, Li C, Sayeeda Z and Assempour N 2017 DrugBank 5 0: a major update to the DrugBank database for 2018 Nucleic Acids Res. 461074

9. Baumann M and Baxendale I R 2013 An overview of the synthetic routes to the best selling drugs containing 6-membered heterocycles Beilstein J. Org. Chem. 92265

10. Bayram M, De Luca L, Massie M B and Gheorghiade M 2005 Reassessment of dobutamine, dopamine, and milrinone in the management of acute heart failure syndromes Am. J. Cardio. 9647

11. Gramec D, Peterlin Mašič L and Sollner Dolenc M 2014 Bioactivation potential of thiophene-containing drugs Chem. Res. Toxicol. 271344

12. Peng Z and Galvin ME 1998 Polymers with high electron affinities for light-emitting diodes Chem. Mater. 101785

13. Percino M J, Chapela V M, Cerón M, SorianoMoro G, Castro M E and Melendez F J 2013 Fluorescence improvement of pyridylacrylonitrile by dimethylaminophenyl-substitutions: The effect of packing modes of conjugated compounds J. Mol. Struct. 1034 238

14. Epstein A J, Wang Y, Jessen S W, Blatchford J W, Gebler D D, Lin L B, Gustafson T L, Swager T M and Macdiarmid A G 1997 Pyridine-based conjugated polymers: Photophysical properties and light-emitting devices Macromol. Symp. 11627

15. Liu M S, Jiang X, Liu S, Herguth P and Jen A K Y 2002 Effect of cyano substituents on electron affinity and electron-transporting properties of conjugated polymers Macromolecules 353532

16. Wang C, Dong H, Hu W, Liu Y and Zhu D 2011 Semiconducting $\pi$-conjugated systems in field-effect transistors: a material odyssey of organic electronics Chem. Rev. 112 2208

17. Percino J, Cerón $\mathrm{M}$, Venkatesan $\mathrm{P}$, Ceballos $\mathrm{P}$, Bañuelos A, Rodríguez O, Siegler M A, Robles F, Chapela V M, Soriano-Moro G, Pérez-Gutiérrez E, Bonilla-Cruz J and Thamotharan S 2017 Two Different Emissions of (2 Z)-2-(4-Bromophenyl)-3-[4(dimethylamino) phenyl] prop-2-enenitrile Due to Crystal Habit and Size: Synthesis, Optical, and Supramolecular Characterization Cryst. Growth Des. 171679

18. Venkatesan $\mathrm{P}$, Cerón $\mathrm{M}$, Thamotharan S, Robles F and Percino M J 2018 Quantitative analysis of weak non-covalent interactions in (Z)-3-(4-halophenyl)2-(pyridin-2/3/4-yl) acrylonitriles CrystEngComm 20 2681

19. Percino M, Chapela V, Montiel L F, Pérez-Gutiérrez E and Maldonado J 2010 Spectroscopic characterization of halogen-and cyano-substituted pyridinevinylenes synthesized without catalyst or solvent Chem. Pap. 64360

20. Percino M, Chapela V, Pérez-Gutiérrez E, Cerón and Soriano G 2011 Synthesis, optical, and spectroscopic characterisation of substituted 3-phenyl-2arylacrylonitriles Chem. Pap. $\mathbf{6 5} 42$

21. Gavezzotti A 2002 Calculation of intermolecular interaction energies by direct numerical integration over electron densities. I. Electrostatic and polarization energies in molecular crystals J. Phys. Chem. B106 4145

22. Gavezzotti A 2003 Calculation of intermolecular interaction energies by direct numerical integration over electron densities. 2. An improved polarization model and the evaluation of dispersion and repulsion energies J. Phys. Chem. B107 2344

23. Gavezzotti A 2011 Efficient computer modeling of organic materials. The atom-atom, Coulomb-LondonPauli (AA-CLP) model for intermolecular electrostaticpolarization, dispersion and repulsion energies New J. Chem. 351360

24. Bader R F 1991 A quantum theory of molecular structure and its applications Chem. Rev. 91893

25. Spackman M A and Jayatilaka D 2009 Hirshfeld surface analysis CrystEngComm 1119

26. Spackman M A and McKinnon J J 2002 Fingerprinting intermolecular interactions in molecular crystals CrystEngComm 4378

27. McKinnon J J, Jayatilaka D and Spackman M A 2007 Towards quantitative analysis of intermolecular interactions with Hirshfeld surfaces Chem. Comm. 373814

28. Sheldrick G M 2008 A short history of SHELX Acta Cryst. A64 112

29. Sheldrick G M 2015 Crystal structure refinement with SHELXL Acta Cryst. C71 3

30. Spek A L 2003 Single-crystal structure validation with the program PLATON J. Appl. Cryst. 367

31. Macrae C F, Edgington P R, McCabe P, Pidcock E, Shields G P, Taylor R, Towler M and Streek J V D 2006 Mercury: visualization and analysis of crystal structures J. Appl. Cryst. 39453

32. Turner M J, McKinnon J J, Wolff S K, Grimwood D J, Spackman P R, Jayatilaka D and Spackman M A 2017 CrystalExplorer17 University of Western Australia.

33. McKinnon J J, Spackman M A and Mitchell A S 2004 Novel tools for visualizing and exploring intermolecular interactions in molecular crystals Acta Cryst. B60 627

34. Boys S F and Bernardi F 1970 The calculation of small molecular interactions by the differences of separate total energies. Some procedures with reduced errors $\mathrm{Mol}$. Phys. 19553

35. Frisch M J, Trucks G W, Schlegel H B, Scuseria G E, Robb M A, Cheeseman J R, Scalmani G, Barone V, Mennucci B, Petersson G A, Nakatsuji H, Caricato M, Li X, Hratchian H P, Izmaylov A F, Bloino J, Zheng G, Sonnenberg J L, Hada M, Ehara M, Toyota K, Fukuda R, Hasegawa J, Ishida M, Nakajima T, Honda Y, Kitao O, Nakai H, Vreven T, Montgomery Jr. J A, Peralta J E, 
Ogliaro F, Bearpark M, Heyd J J, Brothers E, Kudin K N, Staroverov V N, Keith T, Kobayashi R, Normand J, Raghavachari K, Rendell A, Burant J C, Iyengar S S, Tomasi J, Cossi M, Rega N, Millam J M, Klene M, Knox J E, Cross J B, Bakken V, Adamo C, Jaramillo J, Gomperts R, Stratmann R E, Yazyev O, Austin A J, Cammi R, Pomelli C, Ochterski J W, Martin R L, Morokuma K, Zakrzewski V G, Voth G A, Salvador P, Dannenberg J J, Dapprich S, Daniels A D, Farkas O, Foresman J B, Ortiz J V, Cioslowski J. Fox, D J 2013 Gaussian 09, Revision D. 01, Gaussian Inc., Wallingford CT

36. Zhao Y and Truhlar D G 2008 The M06 suite of density functionals for main group thermochemistry, thermochemical kinetics, noncovalent interactions, excited states, and transition elements: two new functionals and systematic testing of four M06-class functionals and 12 other functionals Theo. Chem. Acc. 120215

37. Grimme S, Antony J, Ehrlich S and Krieg H 2010 A consistent and accurate ab initio parametrization of density functional dispersion correction (DFT-D) for the 94 elements H-Pu J. Chem. Phys. 132154104

38. Becke A D 1993 Density-functional thermochemistry. III. The role of exact exchange J. Chem. Phys. 985648

39. Espinosa E, Molins E and Lecomte C 1998 Hydrogen bond strengths revealed by topological analyses of experimentally observed electron densities Chem. Phys. Lett. 285170

40. Bulat F A, Toro-Labbé A, Brinck T, Murray J S and Politzer P 2010. Quantitative analysis of molecular surfaces: areas, volumes, electrostatic potentials and average local ionization energies J. Mol. Model. 161679

41. Percino M J, Cerón M, Rodríguez O, Soriano-Moro G, Castro M E, Chapela V M, Siegler M A and Pérez-Gutiérrez E 2016 Conformational and Molecular Structures of $\alpha, \beta$-Unsaturated Acrylonitrile Derivatives: Photophysical Properties and Their Frontier Orbitals Molecules 21389

42. Percino M J, Cerón M, Ceballos P, Soriano-Moro G, Castro M E, Chapela V M, Bonilla-Cruz J, Reyes-Reyes M, López-Sandoval R and Siegler M A 2014 Important role of molecular packing and intermolecular interactions in two polymorphs of (Z)-2-phenyl-3-(4-(pyridin-2-yl) phenyl) acrylonitrile Preparation, structures, and optical properties J. Mol. Struct. 107874
43. Matta C F, Hernández-Trujillo J, Tang T H and Bader R F 2003 Hydrogen-hydrogen bonding: a stabilizing interaction in molecules and crystals Chem. Eur. J. 9 1940

44. Al-Wahaibi L H, Sujay S, Muthu G G, El-Emam A A, Venkataramanan N S, Al-Omary F A, Ghabbour H A, Percino J and Thamotharan S 2018 Theoretical investigations of two adamantane derivatives: A combined X-ray, DFT, QTAIM analysis and molecular docking J. Mol. Struct. 1159233

45. Thamotharan S, Kothandapani J, Ganesan S S, Venkataramanan N S, Kumar S M, Byrappa K, Percino J and Robles F 2018 Quantitative analysis of intermolecular interactions in 2, 2'-((4-bromophenyl) methylene) bis (3-hydroxy-5, 5-dimethylcyclohex-2-en1-one): insights from crystal structure, PIXEL, Hirshfeld surfaces and QTAIM analysis J. Chem. Sci. 130 20

46. Udayakumar M, Jagatheeswaran K, Ganesan S S, Venkataramanan N S, Kumar S M, Byrappa K and Thamotharan S 2017 Investigation of 9-(2-hydroxy4, 4-dimethyl-6-oxocyclohex-1-en-1-yl)-3, 3-dimethyl2, 3, 4, 9-tetrahydro-1H-xanthen-1-one: Crystal structure, AIM and NBO analysis J. Mol. Struct. 1133510

47. Popelier P L 1998 Characterization of a dihydrogen bond on the basis of the electron density J. Phys. Chem. A102 1873

48. Koch U and Popelier P L 1995 Characterization of CHO hydrogen bonds on the basis of the charge density $J$. Phys. Chem. 999747

49. Munshi P, Thakur T S, Guru Row T N and Desiraju G R 2006 Five varieties of hydrogen bond in 1-formyl-3thiosemicarbazide: an electron density study Acta Cryst. B62 118

50. Munshi P and Guru Row T N 2006 Intra-and intermolecular interactions in small bioactive molecules: cooperative features from experimental and theoretical charge-density analysis Acta Cryst. $\mathbf{B 6 2}$ 612

51. Munshi P, Cameron E, Guru Row T N, Ferrara J D and Cameron T S 2007 Investigation of inter-ion interactions in $N, N, N$ ', $N$ '-tetramethylethylenediammonium dithiocyanate via experimental and theoretical charge density studies J. Phys. Chem. A111 7888 